\title{
Activity of Antioxidant Enzymes under Induced Oxidative Stress
}

\author{
Małgorzata Deska' \\ 1 Central Mining Institute, Department of Water Protection, Plac Gwarków 1, 40-166 Katowice, Poland \\ e-mail:mdeska@gig.eu
}

\begin{abstract}
Reactive oxygen species (ROS) include both oxygen free radicals and highly reactive oxygen compounds (such as ozone, singlet oxygen). They are formed in many metabolic processes, as well as under the influence of various environmental factors. Their impact on cells depends on their concentration and the duration of the process. Excessive level of ROS in a cell leads to oxidative stress. One of the defence mechanisms against ROS corresponds to antioxidant enzymes including SOD and CAT. This paper defines the changes in the activity of antioxidant enzymes caused by oxidative stress induced by nickel and paraquat in tissue of Acheta domesticus L, derived from various development lines. The obtained results defining the activity of SOD and CAT indicated the differences among individual tissues and the midgut showed the highest activity. Increased activity in relation to the control group results of CAT and SOD in the midgut and fat body of B-line individuals treated with pro-oxidant (particularly nickel) and inhibition of the CAT activity in the midgut of L-line crickets influenced by pro-oxidant indicate that the conducted screening changes the biochemical response to the stress factors. Moreover, the obtained results may indicate the relation of the activity of SOD and CAT with the lifespan of the tested insects.
\end{abstract}

Keywords: oxidative stress, nickel, paraquat, reactive oxygen species

\section{INTRODUCTION}

\section{Reactive oxygen species and their sources}

The atoms, molecules or ions that have one or more unpaired electrons on the valence shell are called free radicals. Their unstable state causes that they are very reactive to various cellular molecules including proteins, sugars, lipids and DNA. This in turn damages or changes the properties and consequently causes disorders of the functioning of organelles and whole cells. Apart from free radicals, some other oxygen compounds exhibit high reactivity, such as ozone, singlet oxygen or hydrogen peroxide. Therefore, oxygen radicals as well as other oxygen compounds that show higher reactivity than molecular oxygen in a triplet (basic) state are referred to as reactive oxygen species (ROS) [Próchniak et al. 2016].

The impact of ROS on cells is highly dependent on their concertation or duration of activity. Higher concertation of these molecules causes toxic damages to cells, consequently leading to their destruction, whereas low concertation of ROS may perform physiological functions [Susana et al 2014; Sies 2017]. Small amounts of ROS are required for the proper functioning of the organism as they are involved in the processes that protect the cell against oxidative stress and restore its redox balance [Tvrdá 2011]. They may also perform the functions of second messengers activating signal cascades related to defining the fate of the cell, the process of differentiation, apoptopis (which allows eliminating those cells that have suffered major damage and could pose a potential threat to the body) or proliferation [Finkel and Holbrook 2000; Storz 2006; Rao et al. 2011]. ROS are formed in many biochemical processes such as biological oxidation in the respiratory chain, phagocytosis or oxidation reactions of compounds [Glasauer and Chandel 2013]. The mitochondrial respiratory chain, namely complex I (NADH dehydrogenase) and complex III (cytochrome reductase), is the most important endogenous source of ROS. The superoxide anion radical is formed as a result of reaction of a reduced 
form of ubiquinone with oxygen. Another source of ROS in cells is also xanthine oxidase and both cytochrome P-450 and cytochrome P-450 reductase [Finkel and Holbrook 2000; Ott et al. 2007; Phaniendra et al. 2015; Skulachev 2012; Sies 2018].

The formation of ROS may be also induced by environmental factors, such as xenobiotics and various types of environmental pollution, ultraviolet radiation or ionizing radiation. [Finkel and Holbrook 2000; Pomatto and Davies 2018]. In a cell, xenobiotics go into redox cycles which are driven by its metabolism. An example of this relationship is paraquat, a widely used herbicide (currently banned in EU countries). It belongs to a group of dipyridinium herbicides, which becomes the final acceptor of electrons in the reduction centre of the photosystem I. The resulting paraquat radical cation reacts with oxygen, resulting in regeneration of the initial form of the compound and the formation of a superoxide anion radical [Li et al. 2019; Eddleston 2020].

Transition metal ions (vanadium, chromium, manganese, iron, cobalt, nickel, copper, zinc, molybdenum) are essential components of living organisms. However, they may be oxidized and thus catalyse ROS generating reactions [Valko et al. 2006].

\section{Oxidative Stress}

Excessive production of ROS may cause the so-called oxidative stress. The term oxidative stress in biological and biomedical sciences was used for the first time about 30 years ago and has since been one of the most-studied biological processes [Breitenbach and Eckl 2015]. This condition is the result of excessive activity of reactive species of oxygen (ROS), resulting from the imbalance between the formation of the oxygen free radicals and their removal from cell by the antioxidative systems [Luo et al. 2020]. This imbalance may be both caused by an increase in the amount of ROS in the body and decreased activity of the antioxidative defence mechanisms [Agarwal et al. 2012]. The disruption leads to damages to membrane lipids, amino acids and DNA [Ochsendorf 1999; Luo et al. 2020].

\section{Defence Mechanisms}

Living organisms are equipped with a number of defence mechanisms to maintain the physiological level of ROS. These mechanisms may be divided into three primary groups:

- Prevention - preventing ROS from reacting with biomolecules: enzymes (superoxide dismutase, catalase and glutathione peroxidase).

- Termination - breaking the chains of free radicals reactions and unwanted non-radical oxidation reactions: free radicals scavengers; low weight molecular antioxidants: glutathione, vitamin $\mathrm{C}$ and $\mathrm{E}$, carotenoids.

- Repair - removal of the effects of ROS reactions with biomolecules such as DNA repair enzymes [Tan et al. 2018; Katerji et al. 2019].

The antioxidative defence in animal species studied so far is based on similar enzyme systems. Insects have a set of antioxidative enzymes and low molecular weight antioxidants that protect against both endogenous and environmental origin oxidants. The main antioxidant enzymes that occur in insects are superoxide dismutase, catalase, glutathione transferase, glutathione reductase, as well as a number of antioxidants such as ascorbic acid, glutathione, vitamin E and carotenoids. Despite the relatively low level of metabolism, insects can be strongly exposed to oxidative stress mainly due to the structure of their tracheal system supplying oxygen directly to body cells, which is particularly important during an energy-intensive flight, as well as due to the presence of pro-oxidants in the diet of some herbivorous insects [Felton and Summers 1995].

Antioxidant enzymes participate in the scavenging of ROS generated by xenobiotics, such as paraquat and allele compounds of plant origin, including fumarocoumarins, lignans, acetophenones, thiophenones, phenols or quinones. That is why the antioxidant defence plays a significant role in this case. Large amounts of ROS are formed in the tissues of insects during flights and in some special cases, such as bioluminescence; therefore, the species exhibiting this phenomenon are characterized by much higher SOD activity [Felton and Summers 1995]. Antioxidative enzymes are often used as biomarkers of exposure to toxic substances [Aziz 2020].

Superoxide dismutase and catalase are a fundamental enzyme system aimed at scavenging free radicals formed in cells [Macías-Núñez et al. 2020]. Superoxide dismutase (SOD, E.C.1.15.1.1) is a group of enzymes that catalyse the dismutation reaction of superoxide anion radical. There are two basic forms of superoxide dismutase in 
eukaryotic organisms: SOD-1, which depends on the zinc and copper ions, occurs in the nucleus and cytoplasm ( $\mathrm{Cu}, \mathrm{Zn}-\mathrm{SOD})$ and SOD-2, present in mitochondrial matrix (Mn-SOD). SOD-1 is a homidimer built of two identical subunits with a mass of about $16 \mathrm{kDa}$, whereas SOD-2 is a tetramer composed of four units with a mass of about $20 \mathrm{kDa}$. SOD in insects does not substantially differ from the SOD in vertebrates. There are also reports that both insects and mammals have extracellular SOD (EC-SOD, SOD-3) associated with multi-sugars of the cell surface and has a protective function [Choi 1999].

The second important antioxidative enzyme is catalase (CAT, E.C.1.11.1.6). It is composed of four identical subunits with a molecular weight of about $60 \mathrm{kDa}$. Each subunit has a deeply embedded heme system with a centrally located iron atom. Catalase decomposes hydrogen peroxide in two stages. In the first stage, the hydrogen peroxide is reduced to water in which the iron ion Fe (III) of the heme system in involved. In the second stage, another molecule of hydrogen peroxide is oxidized with the $\mathrm{Fe}(\mathrm{V})-\mathrm{CAT}$, resulting in the formation of molecular oxygen and water. A few studies showed that CAT found in insects is not significantly different from catalase in vertebrates [Sohal 1985]. Some studies on selected groups of invertebrates showed that the form of CAT is a type of catalase that is very similar to peroxidases [Saint-Denis et al. 1998].

\section{Free radicals and their role in the aging process}

Free radicals are one of the important factors that cause damage to molecules, which in turn can contribute to the aging of organisms. Hence, the role of antioxidant enzymes in recent decades has gained a particular interest in the study on the course of the aging process [Tan et al. 2018; Tan and Norhaizan 2019; Luo et al. 2020]. One of the theories of aging - theory of free radicals, claims that it is the formation of reactive species of oxygen (ROS) in the body that may be the main cause of its aging. The consequences of free radicals accumulate with age and indicate a reverse correlation with the potential life expectancy of an organism. This has been proven by studies on the production of ROS (such as superoxide anion radical, hydrogen peroxide or hydroxyl radical) and the protein oxidation process in insect mitochondria [Kasapoglu 2001; Korsloot 2003].
The verification of the free radicals theory has resulted in numerous studies on the relationship between antioxidative enzyme activity and life extension. The research was mainly conducted on model organisms of Drosophila melanogaster, screened in terms of different aging rates and longevity. The screening of vertebrates is more difficult compared to insects, as their lifespan is relatively long. Nevertheless, such experiments are conducted also on mice, because their aging process is similar to that of a human [Chen et al. 2010].The screening of Drosophila melanogaster have been conducted since the 1960s and the methodology for obtaining the lines that differ in life expectancy is currently widely used [Rose et al. 2004; Zhang et al. 2019; Qiu et al. 2020].

There are various methods to assess the exposure to oxidative stress. One of the responses of an organism related to the exposure to different types of xenobiotics is the efficiency of antioxidant enzyme mechanisms. Hence, measuring the activity of antioxidant enzymes including superoxide dismutase (SOD) and catalase (CAT) is a useful biomarker for the body's exposure to oxidative stress [Czerska et al. 2015; Katerji et al. 2019].

Therefore, the main objective of this study is to determine the changes in the antioxidant enzyme activity under the influence of oxidative stress induced by nickel and paraquat in the studied organs of Acheta domesticus L. and to determine the differences in SOD and CAT between the sexes of the examined individuals. Moreover, the tests on individuals from two development lines also made it possible to investigate whether there are differences in the SOD and CAT activity between the crickets from two development lines.

\section{MATERIALS AND METHODS}

\section{Biological material}

The biological material for the study was obtained from 10-day-old individuals (male and female) of house cricket Acheta domesticus L. (Orthoptera: Gryllidae) from two screening lines (B - breeding line and $\mathrm{L}$ - long-lived line screened in terms of extended lifespan). A list of experimental groups is presented in table 1 .

The crickets were grown at a constant temperature of $29.0^{\circ} \mathrm{C} \pm 1.5^{\circ} \mathrm{C}$, with air humidity of about $40 \% \pm 10 \%$ and a $12 \mathrm{~L}: 12 \mathrm{D}$ photoperiod 
Table 1. Experimental groups: Symbols: L - long-lived line, B - breeding line, $\mathrm{F}$ - females, $\mathrm{M}$ - males, $\mathrm{C}$ - control, $\mathrm{P}$ - paraquat, $\mathrm{N}$ - nickel, $\mathrm{M}$ - midgut, $\mathrm{T}-$ Malpighian tubules, $\mathrm{F}-$ fat body

\begin{tabular}{|c|c|c|c|c|}
\hline Line & Sex & Pro-oxidant & Tissue & Code \\
\hline \multirow{18}{*}{ L } & \multirow{9}{*}{$\mathrm{F}$} & \multirow{3}{*}{ C } & $M$ & LCFM \\
\hline & & & $\mathrm{T}$ & LCFT \\
\hline & & & $\mathrm{F}$ & LCFF \\
\hline & & \multirow{3}{*}{$P$} & $\mathrm{M}$ & LPFM \\
\hline & & & $T$ & LPFT \\
\hline & & & $\mathrm{F}$ & LPFF \\
\hline & & \multirow{3}{*}{$\mathrm{N}$} & $M$ & LNFM \\
\hline & & & $T$ & LNFT \\
\hline & & & $\mathrm{F}$ & LNFF \\
\hline & \multirow{9}{*}{ M } & \multirow{3}{*}{ C } & $M$ & LCMM \\
\hline & & & $T$ & LCMT \\
\hline & & & $\mathrm{F}$ & LCMF \\
\hline & & \multirow{3}{*}{$P$} & $\mathrm{M}$ & LPMM \\
\hline & & & $\mathrm{T}$ & LPMT \\
\hline & & & $\mathrm{F}$ & LPMF \\
\hline & & \multirow{3}{*}{$\mathrm{N}$} & $\mathrm{M}$ & LNMM \\
\hline & & & $\mathrm{T}$ & LNMT \\
\hline & & & $\mathrm{F}$ & LNMF \\
\hline \multirow{18}{*}{ B } & \multirow{9}{*}{$F$} & \multirow{3}{*}{ C } & $M$ & BCFM \\
\hline & & & $T$ & BCFT \\
\hline & & & $\mathrm{F}$ & BCFF \\
\hline & & \multirow{3}{*}{$P$} & $\mathrm{M}$ & BPFM \\
\hline & & & $T$ & BPFT \\
\hline & & & $\mathrm{F}$ & BPFF \\
\hline & & \multirow{3}{*}{$\mathrm{N}$} & $\mathrm{M}$ & BNFM \\
\hline & & & $T$ & BNFT \\
\hline & & & $\mathrm{F}$ & BNFF \\
\hline & \multirow{9}{*}{ M } & \multirow{3}{*}{ C } & $M$ & BCMM \\
\hline & & & $\mathrm{T}$ & BCMT \\
\hline & & & $\mathrm{F}$ & BCMF \\
\hline & & \multirow{3}{*}{$P$} & $M$ & BPMM \\
\hline & & & $T$ & BPMT \\
\hline & & & $\mathrm{F}$ & BPMF \\
\hline & & \multirow{3}{*}{$\mathrm{N}$} & $M$ & BNMM \\
\hline & & & $\mathrm{T}$ & BNMT \\
\hline & & & $\mathrm{F}$ & BNMF \\
\hline
\end{tabular}

in plastic insectarium with cardboard mouldings placed inside to increase the surface of locomotion. Murigran laboratory rodent feed and water were provided as needed.

\section{Induction of oxidative stress}

The 10-day L and B-line larvae were divided into 3 research groups: control, treatment with paraquat (1,1'-dimethyl-4,4'-bipyridine) and nickel (nickel chloride). The induction of oxidative stress in the tested organisms was carried out by administering pro-oxidant 1$)$ nickel ( $5 \mu \mathrm{mol}$ $\mathrm{NiCl}_{2} / 1 \mathrm{~g}$ of feed) and 2) paraquat (1 $\mu \mathrm{mol} / 1 \mathrm{~g}$ of feed) with feed. In order to prepare the food, the right amount of pro-oxidant was dissolved in redistilled water; the resulting solution was mixed with proper amount of Murigran ground feed. The food for the control group was a mixture of redistilled water and Murigran feed. Then the homogeneous mixture was dried $\left(40^{\circ} \mathrm{C}, 24 \mathrm{~h}\right)$. The food was prepared as needed, but no less than once a month.

\section{Tissue isolation}

The biological material in the form of postmitochondrial supernatant from the midgut, the 
fat body and Malpighian tubules of 10-day-old Acheta domesticus L. was used for enzymatic assays. The protein concentration in the tested samples was determined according to the Bradford method, using the Coomassie Brilliant Blue G-250 dye (Fluka). A calibration curve was prepared for bovine serum albumin. Absorbance was read on a spectrophotometer $(\lambda=595 \mathrm{~nm})$ at a room temperature.

\section{Enzyme assay}

\section{Specific catalase activity}

The determination of activity of catalase was based on the Aebi method [1984]. This method involves measuring the decrease in absorbance in ultraviolet light $(\lambda=240 \mathrm{~nm})$ as a result of decomposition of hydrogen peroxide by catalase into water and oxygen. The reaction was initiated by adding the supernatant to the reaction mixture. The measurements were performed at $25^{\circ} \mathrm{C}$. The measurements were taken in $0.05 \mathrm{M}$ Sörensen phosphate buffer (pH 7.0) in the appropriate volume (the volume of the buffer depended on the amount of supernatant added) from 1.950 to $1.998 \mathrm{ml}$ and $1 \mathrm{ml}$ of $\mathrm{H}_{2} \mathrm{O}_{2}$ in Sörensen buffer (final concentration in the solution was $10 \mathrm{mM}$ ). The final volume of the reaction mixture amounted to $3 \mathrm{ml}$. In the case of the blank, $1 \mathrm{~mL}$ of Sörensen buffer was added instead of the $\mathrm{H}_{2} \mathrm{O}_{2}$ solution. The volume of the supernatant added to the reaction mixture was adjusted so that the rate of decrease in the absorbance of hydrogen peroxide was about $0.036 \mathrm{JA} / \mathrm{min}$ and was a linear function of time. The measurement was performed on a spectrophotometer for 30 seconds in quartz cuvettes relative to the blank. The specific activity of catalase was expressed in $\mu \mathrm{mol} \mathrm{H}_{2} \mathrm{O}_{2} / \mathrm{min} / \mathrm{mg}$ of protein.

\section{Specific activity of superoxide dismutase}

The adrenaline method developed by Misra and Fridovich [1972] with the modification of Matkovics et al. [1977] was used to determine the activity of superoxide dismutase. This method is based on intermediate reactions producing $\mathrm{O}^{2 \cdot-}$ and using the ion as a catalytic agent for subsequent stages of the reaction. The source of superoxide ions as well as of an indicator product, which is red-brown adrenochrome, is the autooxidation reaction of adrenaline. SOD removes the superoxide ion, which is manifested by the inhibition of the indicator reaction. The supernatant dilutions were selected so that the adrenaline autooxidation reaction was inhibited by approximately $50 \%$. The measurements were conducted in $0.1 \mathrm{M}$ carbonate buffer in a variable volume (the volume of the buffer depended on the amount of supernatant added) from 1.450 to $1.498 \mathrm{ml}(\mathrm{pH}$ 10.2) with $0.02 \mathrm{M}$ EDTA and $0.05 \mathrm{ml} 10 \mathrm{mM}$ adrenaline solution (causing the required autooxidation rate of $25 \mathrm{mODU} / \mathrm{min}$ ) in $0.01 \mathrm{M} \mathrm{HCl}$ (pH 2.0). The volume of post-mitochondrial supernatant added to the reaction mixture depended on the SOD activity and the concentration of protein in a given tissue and ranged between 0.05 and $0.002 \mathrm{ml}$. The final volume of the reaction mixture amounted to $2 \mathrm{ml}$. In the case of the blank, the same amount of carbonate buffer was added instead of the supernatant. The absorbance change of the blank was $0.025 \mathrm{~A} / \mathrm{min}$. The absorbance of the test sample was measured for $4 \mathrm{~min}$ at $30^{\circ} \mathrm{C}$, at a wavelength of $480 \mathrm{~nm}$, using a spectrophotometer. SOD specific activity is expressed in $\mathrm{JA} / \mathrm{mg}$ protein $/ \mathrm{min}$.

\section{RESULTS AND DISCUSSION}

\section{Differences in the activity of SOD and CAT between sexes}

The activity of the enzymes did not differ significantly between males and females within individual research groups $(p=0.7443$, the KruskallWallis test). Considering the above, the gender division in individual research groups in further analyses was omitted. In the studies on the pod of Acanthoscelides obtectus (Coleoptera: Bruchidae), the females of both the long-lived and short-lived lines had several times higher catalase activity than males, but no significant differences were found between the lines. However, it should be noted that the study object in this work (hemimetabolic species) differs in the type of development from the species used in the study (holometabolic species) [Seslija 1999].

\section{SOD and CAT activity}

The specific activity of SOD and CAT showed differences between the analysed tissues. The specific activity of the enzymes in the control groups was significantly higher in the midgut compared 
to Malpighian tubules and fat body. The middle intestine was characterized by about 1.5 times higher SOD activity and about 5 times higher CAT activity in relation to other organs (Fig. 1, 2). Malpighian tubules and fat body did not differ significantly. The order in the specific activity of SOD and CAT in the examined organs was as follows: $\mathrm{M}>>\mathrm{T}>=\mathrm{F}$, where $\mathrm{M}-$ midgut, $\mathrm{T}-\mathrm{Mal}-$ pighian tubules, $\mathrm{F}$ - fat body. Paraquat caused a significant decrease in SOD activity in the midgut and Malpighian tubules in the L-line crickets, whereas in the fat body of the L-line insects and in all organs of the tested B-line insects did not cause significant changes in activity (Fig. 1,2). Paraquat intoxication resulted in a significant decrease in CAT activity only in the midgut of the L-line insects (Fig. 2).

Nickel significantly increased the SOD activity in the midgut in both tested lines. In the $\mathrm{L}$ and B-line crickets, nickel intoxication caused a slight decrease in the SOD activity in Malpighian tubules. In turn, it did not cause significant differences in the activity of SOD in the fat body in both lines (Fig. 1). Nickel intoxication caused a significant decrease in the CAT activity in the midgut of the L-line crickets. It did not cause significant changes in the activity in Malpighian tubules and fat body (Fig. 2). The strongest effect of nickel and paraquat was observed in the midgut.

The specific activity of SOD and CAT in the tested tissue does not in fact show a strong correlation. The exception is the midgut of paraquat treated insect where both the L and B-line showed a high SOD and CAT specific activity correlation. In addition, a high correlation between the activity of that enzymes was shown in the fat body of the L-line individuals treated with nickel and non-intoxicated, and in Malpighian tubules in nickel group (Tab. 2).

Considering the routes of entry of pro-oxidants into the organism of terrestrial insects, high specific activity of antioxidative enzymes (as well as other detoxification enzymes) can be expected, mainly in the epithelium of the midgut, possibly also in the fat body, due to its metabolic functions. The results obtained in the paper are

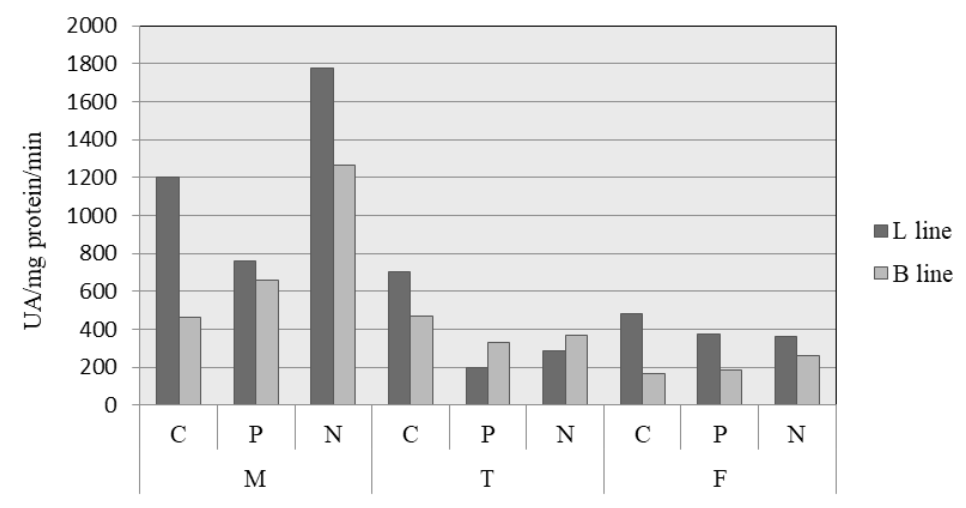

Fig. 1. Specific activity of superoxide dismutase in the tested organs of crickets from the long-lived line (L) and breeding line (B). Symbols: $\mathrm{M}$ - midgut, $\mathrm{T}$ - Malpighian tubules, $\mathrm{T}$ - fat body, $\mathrm{P}$ - paraquat, $\mathrm{N}$ - nickel, $\mathrm{C}$ - control

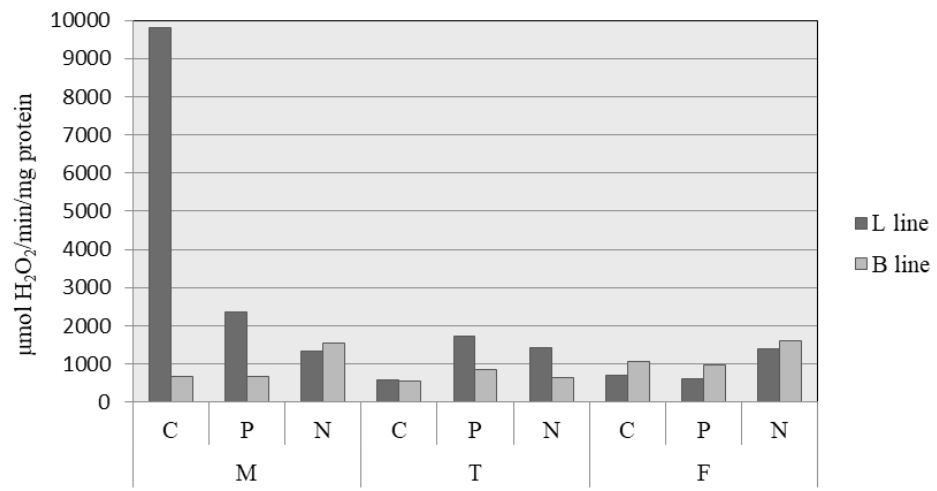

Fig. 2. Specific activity of catalase in the tested organs of crickets from the long-lived line (L) and breeding line (B). Symbols: $\mathrm{M}$ - midgut, $\mathrm{T}$ - Malpighian tubules, $\mathrm{F}-$ fat body, $\mathrm{P}$ - paraquat, $\mathrm{N}$ - nickel, $\mathrm{C}-$ control 
Table 2. A list of high correlations between SOD and CAT activity in the analysed tissues of the crickets from the control group and treated with pro-oxidant. The coefficient of correlation (r), determination $\left(\mathrm{R}_{2}\right)$ and significance (p) are given. Group codes see in Table $\mathbf{1}$

\begin{tabular}{|c|c|c|c|c|}
\hline Group code & Regression Equation & $r$ & $\mathrm{R}_{2}$ & $\mathrm{p}$ \\
\hline LPM & CAT $=1.382 \times$ SOD+1313.85 & 0.824 & 0.679 & 0.0034 \\
\hline LPF & CAT $=1.030 \times$ SOD+230.43 & 0.735 & 0.54 & 0.0154 \\
\hline LNT & CAT $=-4.447 \times$ SOD+2704.97 & 0.626 & 0.392 & 0.0528 \\
\hline LKF & CAT $=1.063 \times$ SOD+179.55 & 0.803 & 0.645 & 0.0051 \\
\hline BPM & CAT $=-0.703 \times$ SOD+1142.58 & 0.918 & 0.843 & 0.0000 \\
\hline BNT & CAT $=1.172 \times$ SOD+210.80 & 0.501 & 0.251 & 0.0680 \\
\hline
\end{tabular}

consistent with this approach - the middle intestine was characterized by the highest specific activity of SOD among the examined organs. The specific activity of both SOD and CAT in the fat body and in Malpighian tubules were similar. The very high activity of catalase in the midgut in the control group from the L-line individuals is noteworthy; it was nearly 5 times higher than in the tissue of the individuals from other groups. High CAT activity in the midgut was also obtained in the studies on Trichoplusia ni, which probably could be the result of a diet of plant origin rich in pro-oxidants. High CAT activity in the midgut and Malpighian tubules may be associated with the presence of a large number of mitochondria in their cells [Ahmad et al. 1991].

As a result of the dismutation reaction of the superoxide anion radical catalysed by superoxide dismutase, hydrogen peroxide is formed, which is then converted by catalase to water and oxygen. It can therefore be concluded that the increase in the SOD activity should be accompanied by an increase in the CAT activity. Only the midgut in paraquat-treated groups and the fat body in longlived nickel and control individuals had a high correlation between the SOD and CAT activity. In these cases, it can be concluded that the whole amount of hydrogen peroxide as a product of the SOD-catalysed reaction is then broken down by CAT. A high correlation may therefore indicate a functional relationship of these enzymes; its lack in turn may indicate the participation of other antioxidative mechanisms.

\section{Antioxidant enzyme activity in various Acheta domesticus L. lines}

The concept that the activity of antioxidant enzymes, mainly superoxide dismutase and catalase, may be linked to life expectancy and is verified by two separate research approaches. One of them is the analysis of possible changes in the activity of antioxidant enzymes in the process of multi-generational screening of animals in terms of longevity. The other research approach is based on overexpressing or silencing genes encoding these enzymes and analysing the survival of genetically modified animals [Arking 2006; Zhang et al 2019].

This study compares the activity of the enzymes between the analysed lines. The two tested lines differ significantly in the activity of antioxidant enzymes in individual organs, with higher activity in the L-line than in the B-line individuals. Significant differences in the SOD and CAT activity between the tested lines were found in the case of control insects than those treated with the nickel and paraquat (Fig. 3, 4).

The free radical theory states that the high activity of these enzymes, mainly superoxide dismutase and catalase, plays an important role in preventing aging. Numerous studies on the relationship between the antioxidative enzyme activity and life extension have been conducted to verify the free radicals theory. The model organism in the study of the aging processes in insects was mainly Drosophila melanogaster [Liu et al 2018; Lee and Min 2019]. Screening of insects in terms of extended life is one of the methods that allow the study of the mechanisms responsible for the aging processes, as well as substances that can at least potentially delay or accelerate these processes. According to the stochastic theories of aging, the survival of the organism should be positively correlated with the effectiveness of defence against stress, mainly the oxidative stress. The results obtained in this study indicate that L-line individuals under oxidative stress conditions have greater antioxidative defence capabilities than the crickets from the reference breed, although it can be assumed that SOD and CAT do not play a key role in determining longevity, but are part of a more complex adaptation strategy. 


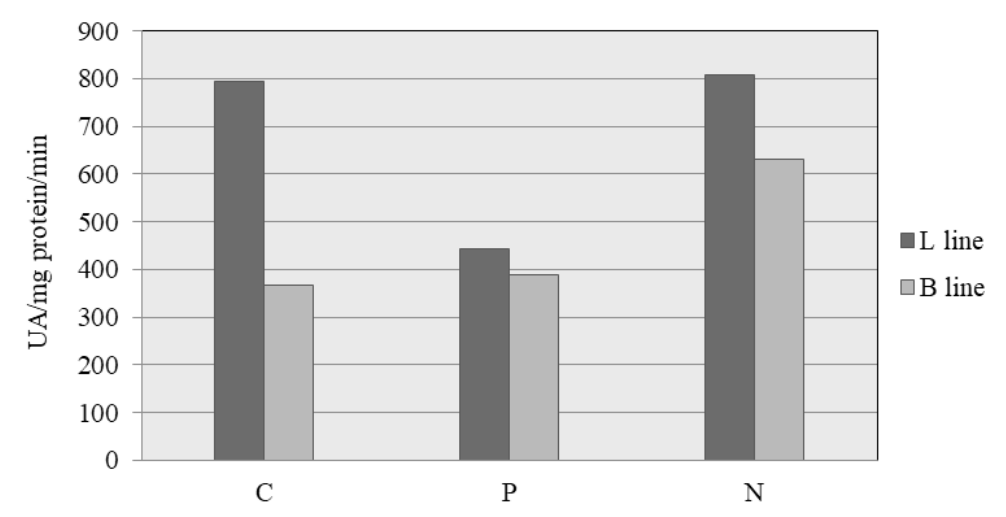

Fig. 3. Specific activity of superoxide dismutase in control (C), paraquat (P) and nickel (N) groups from the long-lived (L) and general breeding line (B)

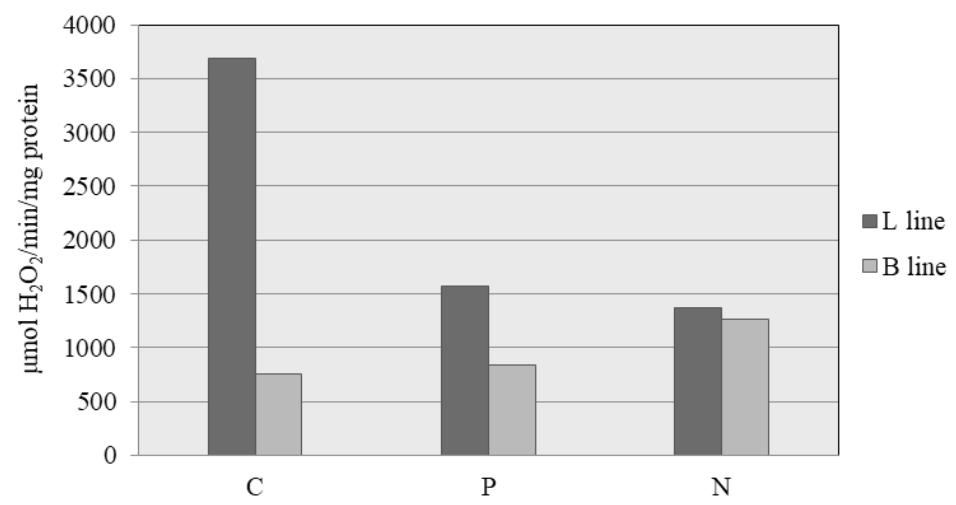

Fig. 4. Specific activity of catalase in control (C), paraquat (P) and nickel (N) groups from the long-lived (L) and general breeding line (B)

Many studies exploring this topic confirm the relationship between the antioxidant enzyme activity and life expectancy. Arking [2000] showed that increased expression of antioxidant enzyme genes - superoxide dismutase and catalase in $D$. melanogaster and, consequently, increased resistance to oxidative stress resulted in prolonged life [Arking 2000]. In turn, the studies conducted by Mackay and Bewley showed that in the mutants of the same species, a reduction of the catalase expression resulted in shortened lifespan [Mackay and Bewley 1989]. The mutants with overexpression of $\mathrm{Cu}, \mathrm{Zn}$-SOD were characterized by life extension, while with reduced expression of Mn-SOD - by shortened lifespan [Kirby et al. 2002; Parkes et al. 1998]. The significant reduction in the Mn-SOD expression in D. melanogaster caused premature neurodegenerations and a much shorter life expectancy [Paul et al. 2007]. Orr and Sohal [1994] conducted research on flies with an additional copy of both the antioxidant enzymes $\mathrm{Cu}, \mathrm{Zn}-\mathrm{SOD}$ and CAT. The flies were characterized by a $34 \%$ increase in lifespan relative to the control lines with a single gene copy, as well showed slowed down rate of natural aging. Such flies also exhibited increased motor activity and a lower level of oxidative damage accumulation [Orr and Sohal 1994]. In the studies in which only one of the genes was amplified, either $\mathrm{Cu}, \mathrm{Zn}$-SOD or CAT, no effect of such manipulation on life expectancy was observed [Orr and Sohal 1994; Orr and Sohal 2003]. A different result was obtained in transgenic fruit flies with overexpression of cytoplasmic superoxide dismutase (Cu, Zn-SOD). Their lifespan increased by nearly $50 \%$ [Aigaki et al. 2002], whereas in the case of the Mn-SOD overexpression, by about $15 \%$ [Sun et al. 2002]. There are also few literature reports that negate the relationship between the activity of antioxidant enzymes and lifespan and aging. Mockett showed that the D. melanogaster individuals from the selected short-lived line were characterized by higher SOD and CAT activity compared to the long-lived line of the same species [Mockett et al. 2001]. 


\section{CONCLUSION}

The paper presents the changes in the activity of antioxidant enzymes under the nickel and paraquat-induced oxidative stress in the selected tissues of cricket (Acheta domesticus L.) from two lines. The research approach used in this study allowed drawing the following conclusions:

1. The highest activity of the enzymes (SOD and $\mathrm{CAT}$ ) in the midgut may indicate the significant role of this organ in neutralizing the effects of free radicals reactions.

2. Higher SOD and CAT activity in the L-line crickets compared to a general breeding group suggests a relationship between these enzymes and the lifespan of Acheta domesticus L. although it can be assumed that antioxidant enzymes, at least SOD and CAT, do not play the only and crucial one, but they are components of a more complex defence strategy.

3. In the studied groups, no differences between sexes were found in terms of sensitivity to oxidative stress measured only as the activity of the antioxidant enzymes - superoxide dismutase and catalase.

\section{Acknowledgments}

This work was supported by the Polish Ministry of Science and Higher Education in the framework of the research work [No 11358019-343], in the Central Mining Institute in Poland.

\section{REFERENCES}

1. Agarwal A., Aponte-Mellado A., Premkumar B.J., Shaman A. \& Gupta S. 2012. The effects of oxidative stress on female reproduction: a review. Reprod Biol Endocrinol, 10(49), 1-31.

2. Ahmad A., Duval D. L., Weinhold, L.C. \& Pardini R.S. 1991. Cabbage looper antioxidant enzymes: tissue specifity. Insect Biochemistry, 21, 563-572.

3. Aigaki T., Seong K., \& Matsuo T. 2002. Longevity determination genes in Drosophila melanogaster. Mech Ageing Dev., 123(12), 1531-1541.

4. Arking R. 2006. The Biology of Aging. Observations and Principles (3rd edition). Oxford University Press.

5. Arking R., Burde V., Graves K., Hari R., Feldman E., Zeevi A., Soliman S., Saraiya A., Buck S., Vettraino J., Sathrasala K., Wehr N. \& Levine R.L. 2000. Forward and reverse selection for longevity in Drosophila is characterized by alteration of antioxidant gene expression and oxidative damage patterns. Exp. Gerontol., 2(35), 167-185.

6. Aziz N., Butt A. \& Elsheikha H.M. 2020. Antioxidant enzymes as biomarkers of $\mathrm{Cu}$ and $\mathrm{Pb}$ exposure in the ground spiders Lycosa terrestris and Pardosa birmanica. Ecotoxicology and Environmental Safety, 190(1), 110054.

7. Breitenbach M. \& Eckl P. 2015. Introduction to Oxidative Stress in Biomedical and Biological Research. Biomolecules, 5(2), 1169-77.

8. Choi J., Roche H., \& Caquet T. 1999. Characterization of superoxide dismutase activity in Chironomus riparius Mg. (Diptera, Chironomidae) larvae - a potential biomarker. Biochem. Physiol. C. 124(1), 73-81.

9. Czerska M., Mikołajewska K., Zieliński M., Gromadzińska J. \& Wąsowicz W. 2015. Today's Oxidative Stress Markers. Medycyna Pracy, 66(3), 393-405.

10. Eddleston M. 2020. Poisoning by pesticides. Medicine. 48(3), 214-217.

11. Felton G.W., \& Summers C. B. 1995. Antioxidant systems in insects. Archives of Insect Biochemistry and Physiology, 29(2),187-197.

12. Finkel T., Holbrook N.J. 2000. Oxidants, oxidative stress and the biology of ageing. Nature, 408(6809), 239-47.

13. Glasauer A., \& Chandel N.S. 2013. ROS. Current Biology, 23(3), 100-101.

14. Kasapoglu M., \& Ozben T. 2001. Alterations of antioxidant enzyme and oxidative stress markers in aging. Experimental Gerontology, 36(2), 209-220.

15. Katerji M., Filippoav M. \& Duerksen-Hughes P. 2019. Approaches and Methods to Measure Oxidative Stress in Clinical Samples: Research Applications in the Cancer Field, Oxidative Medicine and Cellular Longevity, 2019, 1-29.

16. Kirby K., Hu J., Hilliker A.J. \& Phillips J.P. 2002. RNA interference-mediated silencing of SOD2 in Drosophila leads to early adult-onset mortality and elevated endogenous oxidative stress. Proc. Natl. Acad. Sci. USA, 99(25), 16162-16167.

17. Korsloot A., van Gestel C.A. \& van Straalen N. 2004. Environmental stress and cellular response in Arthropods. CRC Press.

18. Lee S.H. \& Min K-J. 2019. Drosophila melanogaster as a model system in the study of pharmacological interventions in aging. Translational Medicine of Aging, 3, 98-103.

19. Li H., Hong T., Zhu Q., Wang S., Huang T., Li X., Lian Q., Ge R-S. 2019.Paraquat exposure delays late-stage Leydig cell differentiation in rats during puberty. Environmental Pollution. 255, 113316.

20. Liu X., Liu M., Tang C., Xiang Z., Li Q., Ruan X., Xiong K., Zheng L. 2018. Overexpression of Nmnat improves the adaption of health span in aging Drosophila. Experimental Gerontology, 108, 276-283.

21. Luo J., Mills K., le Cessie S., Noordam R. \& van 
Heemst D. 2020. Ageing, age-related diseases and oxidative stress: What to do next? Ageing Research Reviews, 5, 100982.

22. Macías-Núñez J.F., Gregori J-A.A. López-Novoa J-M. 2020. Biology of the Aging Process. Encyclopedia of Biomedical Gerontology. 272-295.

23. Mackay W.J., \& Bewley G.C. 1989. The genetics of catalase in Drosophila melanogaster: isolation and characterization of a catalase mic mutants. Genetics, 122(3), 643-652.

24. Marinho H.S., Real C., Cyrne L., Soares H., Antunes F. 2014. Hydrogen peroxide sensing, signaling and regulation of transcription factors. Redox Biology, 2, 535-562.

25. Mockett R.J., Orr W.C., Rahmandar J.J., Sohal B.H. \& Sohal R.S. 2001. Antioxidant status and stress resistance in long- and short lived lines of Drosophila melanogaster. Exp. Geront., 36(3), 441-463.

26. Ochsendorf, F.R. 1999. Infections in the male genital tract and reactive oxygen species. Hum Reprod Update, 5(5), 399-420.

27. Orr W.C. \& Sohal R.C. 1994. Extension of lifespan by overexpression of superoxide dismutase and catalase in Drosophila melanogaster. Science, 263(5150), 1128-1130.

28. Orr W.C., \& Sohal R.S. 2003. Does overexpression of $\mathrm{Cu}, \mathrm{Zn}-\mathrm{SOD}$ extend life span in Drosophila. Exp. Gerontol. 38 (3), 227-230.

29. Ott, M., Gogvadze, V., Orrenius, S. \& Zhivotovsky, B. (2007) Mitochondria, Oxidative Stress and Cell Death. Apoptosis, 12, 913-922.

30. Parkes T. L., Elia A.J., Dickinson D., Hilliker A.J., Phillips J.P., Boulianne G.L. 1998. Extension of Drosophila lifespan by overexpression of human SOD1 in motoneurons. Nat. Genet., 19(2), 171-174.

31. Paul A., Belton A., Nag S., Martin I., Grotewiel M. S. \& Duttaroy A. 2007. Reduced mitochondrial SOD displays mortality characteristics reminiscent of natural aging. Mech. Ageing Dev., 128(911-12), 706-716.

32. Phaniendra A., Jestadi D.B., Periyasamy L. 2015. Free radicals: properties, sources, targets, and their implication in various diseases. Indian J Clin Biochem., 30(1), 11-26.

33. Pomatto L.C.D. \& Davies K.J.A. 2018. Adaptive homeostasis and the free radical theory of ageing. Free Radical Biology and Medicine. 124(20), 420-430

34. Pruchniak M.P., Araźna M. \& Demkow U. 2016. Biochemistry of Oxidative Stress. Advs. Exp. Medicine, Biology - Neuroscience and Respiration, 17, 9-19.

35. Rao P.S, Kalva S., Yerramilli A., Mamidi S. 2011. Free Radicals and Tissue Damage: Role of Antioxidants. Free Radicals and Antioxidants. 1(4), 2-7.

36. Qiu W., Chen X., Tian Y., Wu D., Du M. \&Wang S. 2020. Protection against oxidative stress and antiaging effect in Drosophila of royal jelly-collagen peptide. Food Chem Toxicol.,135, 110881.

37. Rose M.R., Passananti H.B. \& Matos M. 2004. Methuselah flies: A case study in the evolution of aging. World Scientific Publishing.

38. Saint-Denis M., Labrot F., Narbonne J.F. \& Ribera D. 1998. Glutathione, glutathione-related enzymes, and catalase activities in the earthworm Eisenia fetida andrei. Arch Environ Contam Toxicol., 35(4), 602-14.

39. Seslija D., Blagojevic D., Spasic D. \& Tucic M. 1999. Activity of superoxide dismutase and catalase in the bean weevil (Acanthoscelides obtectus) selected for postponed senescence. Exp. Geront., 34(2), 185-195.

40. Sies H. 2017. Hydrogen peroxide as a central redox signaling molecule in physiological oxidative stress: Oxidative eustress. Redox Biol. 11, 613-619.

41. Sies H., 2018. On the history of oxidative stress: Concept and some aspects of current development. Current Opinion in Toxicology, 7, 122-126.

42. Skulachev V.P. 2012. Mitochondria-targeted antioxidants as promising drugs for treatment of agerelated brain diseases. J Alzheimers Dis., 28(2), 283-9.

43. Sohal R.S.1985. Aging in insects. In G. A. Kerkut, Gilbert L. I. (Ed.) Comprehensive insect physiology biochemistry and pharmacology. Volume 10, Biochemistry (pp. 603-61). Pergamon Press.

44. Storz P. 2006. Reactive oxygen species-mediated mitochondria-to-nucleus signaling: a key to aging and radical-caused diseases. Sci STKE, 2006(332), 1945-0877.

45. Sun J., Folk D., Bradley T.J. \& Tower J. 2002. Induced overexpression of mitochondrial Mn-Superoxide dismutase extends the life span of adult Drosophila melanogaster. Genetics, 161(2), 661-672.

46. Tan B.L. \& Norhaizan M.E. 2019. Carotenoids: How Effective Are They to Prevent Age-Related Diseases? Molecules. 9, 1-23.

47. Tan B.L., Norhaizan M.E., Liew W.P. \& Rahman H.S. 2018. Antioxidant and Oxidative Stress: A Mutual Interplay in Age-Related Diseases. Front Pharmacol., 16(9), 1162.

48. Tvrdá E., Kňažická Z, Bárdos L., Massányi P., Lukáč N. 2011. Impact of oxidative stress on male fertility - a review. Acta Veterinaria Hungarica, 59(4), 465-484.

49. Valko M., Rhodes C. J., Moncola J., Izakovic M., Mazur M. 2006. Free radicals, metals and antioxidants in oxidative stress-induced cancer. ChemicoBiological Interactions, 160, 1-40.

50. Zhang, C., Liang, W., Wang, H., Yang, Y., Wang T., Wang S., Yang Y., Wang T., Wang S., Wang X., Wang Y., Feng H. 2019. $\gamma$-Oryzanol mitigates oxidative stress and prevents mutant SOD1-Related neurotoxicity in Drosophila and cell models of amyotrophic lateral sclerosis. Neuropharmacology, 160, 107777. 